\title{
Consequences of Styrene monomer leakage into the atmosphere- a damage to the human beings
}

\begin{abstract}
India has been facing many problems in recent times due to pandemic Covid-19, pollution, population and also many other natural disasters. In addition to these problems, the country is also facing some tragedies such as leakage of gases from industries and blasts. Many gas leakages and blasts were seen in India from the last few decades. Recently, the Visakhapatnam in Andhra Pradesh, India also experienced a gas leakage into atmosphere, which is a dangerous chemical gas i.e styrene from Polymer Company named LG polymer India Company limited on May $7^{\text {th }}$ 2020. LG polymers manufacture plastics and expandable plastics using styrene monomer as raw material. Many people were affected and died due to this leakage of dangerous chemical gas which was released from the polymer industry at early hours of morning. The gas leakage has spread to many nearby villages and has spread to many kilometres. Mainly respiratory problems, eye irritation and skin irritation are the symptoms of the exposure to styrene. Long exposure to this chemical gas may cause the respiratory diseases that effect during lifetime. There should be some environmental measurements and remedies should be taken by the government and also by the people in order to overcome these types of situations.
\end{abstract}

Keywords: consequences, leakage, polystyrene, styrene monomer
Volume 5 Issue 6 - 2020

\author{
Gonamanda Satya Sree, Kapilavayi Venkata \\ Basava Ranjitha, Boggu Jagan Mohan Reddy \\ Department of Chemistry, Adikavi Nannaya University, India
}

\begin{abstract}
Correspondence: Boggu Jagan Mohan Reddy,
Department of Chemistry, Adikavi Nannaya University,

Rajahmahendravaram,533296, India, Tel 9347I53270,
\end{abstract}

Email drbjaganreddy@gmail.com Received: November 27, 2020 | Published: December 18,
2020

(eywords: consequences, leakage, polystyiene, styrene monomer

\section{Introduction}

Visakhapatnam is a fast-growing metropolitan city that has more attracted by industries due to facilities to establish their values. Industrial growth in Visakhapatnam city is noticeable to urban agglomeration in population and the whole city is at a $10 \mathrm{~km}$ distance from the Bay of Bengal shore. ${ }^{1}$ Due to various industries like petroleum refineries, steel, zinc, and fertilizer plants, polymer, cement factories, dairies there was a drastic deterioration of air, water quality. ${ }^{2}$ The industrial emissions have a combined deteriorating effect on the human health and well-being of the local communities, and mainly weaker sections are more disposed to these adverse impacts.

Recently the poisonous gas namely styrene was leaked on $07^{\text {th }}$ May 2020 in Visakhapatnam, Andhra Pradesh (Figure 1(a)). So far, 12 individuals have died and people in hundreds number were infected. The tragedy in Vishakhapatnam shows its impact on five kilometer surroundings and affecting people in thousands. ${ }^{3}$ Previously, in India, massive chemical gas (Methyl-Isocyanate, MIC) tragedy happened at
Bhopal in 1984 and 8000 people died in the first week and 5lakhs of the population were affected by the MIC gas. ${ }^{4}$ And another gas leak was on 2014, June $27^{\text {th }}$ was the explosion of GAIL pipeline, an enormous fire broke out succeeding a heavy blast in Gas Authority of India Limited (GAIL) underground gas Pipeline i.e about 18" size at Nagaram, East Godavari district which is in Andhra Pradesh, India in which about 15 people have died and many got injured. ${ }^{5}$ There are several other gas leaks in which many people were injured and many people died. Some of the leaks are Bhilai steel plant gas outflow in the year 2014, Delhi gas leakage in the year 2017.

Similarly, the styrene gas tragedy in Visakhapatnam shows the leakage of styrene gas from LG Polymer India Private Limited (LGPI) as shown in Figure 1(b). LGPI is located in the RRV Puram which is part of Visakhapatnam and leads in the development, manufacture and services in the field of polymers. ${ }^{6}$ Presently LGPI is one of the prominent and leading manufacturers of Polystyrene as well as expandable Polystyrene in India.
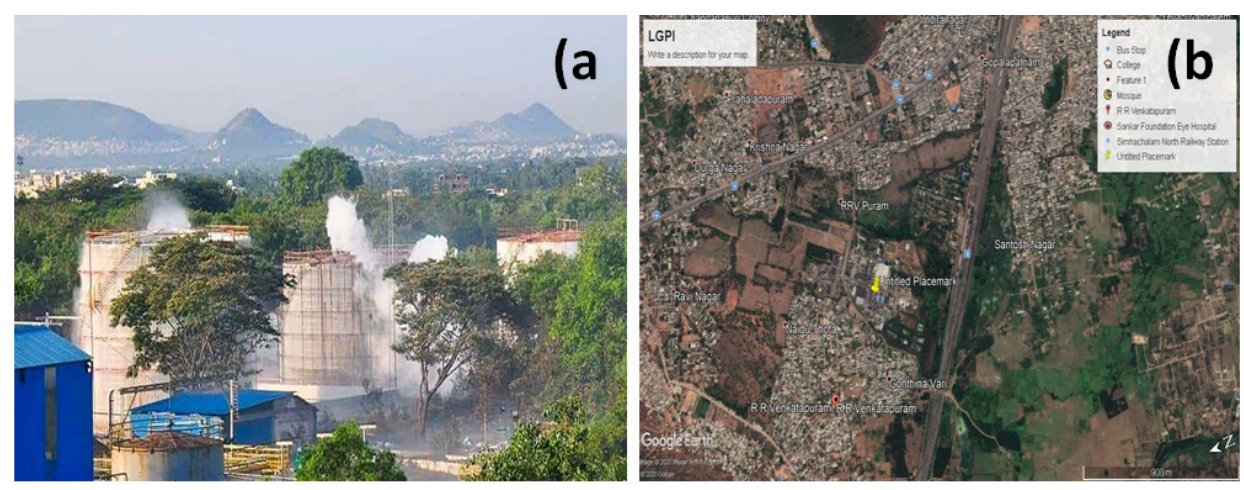

Figure I The styrene gas tragedy in Visakhapatnam shows the leakage of styrene gas from LG Polymer India Private Limited (LGPI). 


\section{Preparation of styrene}

For the complete production of Styrene ${ }^{7}$ involves three steps i.e. firstly preparation of ethyl benzene followed by the ethylbenzene dehydrogenation for styrene and the final step is the purification of the styrene.

a) Synthesis of ethyl benzene: Ethyl benzene is prepared by the reaction of ethylene and benzene in the presence of a Friedalcrafts alkylation catalyst such as Aluminium Chloride at about $95^{\circ} \mathrm{C}(7)$

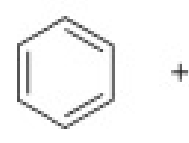

Benzene

\section{$\mathrm{CH}_{2}=\mathrm{CH}_{2}$}

Ethylene<smiles>CCc1ccccc1</smiles>

Ethyl benzene

b) Ethyl benzene dehydrogenation: By the process of dehydrogenation of the ethyl benzene crude Styrene is formed (7)<smiles>CCc1ccccc1</smiles>

\section{Ethylbenzene}

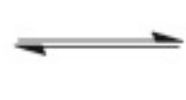

) Puri

Purification of styrene: By the process of dehydrogenation, crude styrene is formed. The obtained product consists of nearly $61 \%$ ethyl benzene and $37 \%$ styrene $\& 2 \%$ of aromatic hydrocarbons such as benzene. As the boiling point of the styrene is very high $\left(145.2^{\circ} \mathrm{C}\right)$, the purification is very difficult. ${ }^{8}$

\section{What happens in atmosphere if Styrene leak?}

Styrene is a volatile organic compound and it is a liquid with a high boiling point. Air pollution modeller Awkash Kumar said that "Styrene in the air on 7 may 2020 when the leak was occurring could have been over $20 \mathrm{ppm}$ up to $2 \mathrm{~km}$ of the LGPI, assuming an hour's leak and effected about 5 villages (R.R.Venkatapuram, Padmapuram, BC Colony, Gopalapatnam and kampara palem) around. Significantly high and more levels of pollutant dispersal could have led people to fall unconscious,".

Besides, the real-time ambient air assessment and monitoring stations network of the Central Pollution Control Board (CPCB) monitors three VOCs such as Toluene $(\mathrm{C} 7 \mathrm{H} 8)$, Benzene $\left(\mathrm{C}_{6} \mathrm{H}_{6}\right)$, Xylene (C8H10) in Visakhapatnam, $14 \mathrm{~km}$ downstream of the spot where the leakage of gas incident happened and the results shown xylene levels up to $18 \mathrm{ppb}$, toluene levels up to $35 \mathrm{ppb}$ and benzene levels up to $12 \mathrm{ppb}$ (Figure 2). After gas leakage it may spread to $5 \mathrm{~km}$ surroundings places which have a dense population as seen in Figure 2. Once vaporises the styrene in atmosphere, it may combine or react with other VOCs and travel long range. These vapours may fall on the water bodies of rivers or lakes which are the great sink for drinking water, more chances to pollute.

\section{Health effects of Styrene on human beings}

According to the United States Environmental Protection Agency (USEPA), short-term contact with low levels of styrene in humans will irritate to the mucous membrane and eyes, and also gastrointestinal effects. On the other side, long-term exposure and contact with styrene results in severe effects on the Central Nervous System (CNS), leading to fatigue, headaches, weakness, loss of hearing, nerve damage and also depression. ${ }^{9}$ According to the Health and Safety Executive, a UK government agency is responsible for regulation and administration of work-place health, safety, and welfare, this chemical can cause loss of consciousness and even death at high exposure levels.

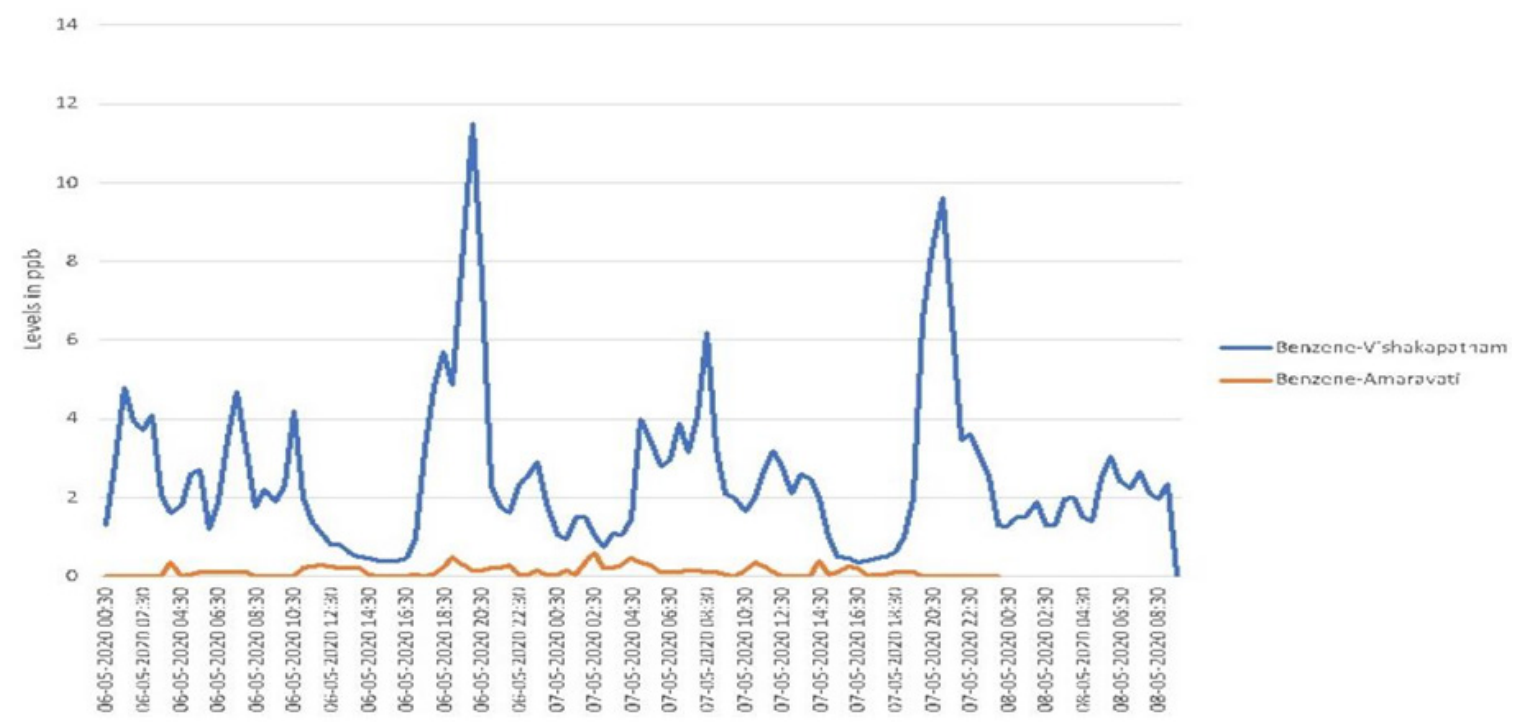

Figure $\mathbf{2}$ The benzene levels in ppb shown in Vishakhapatnam and Amaravati.

Styrene is toxic but it gives a severe effect on humans by ingestion or inhalation. Acute (short-term) exposure or contact to the styrene by humans may cause respiratory problems, eye irritation and also gastrointestinal effects. ${ }^{9}$ Styrene gas effects mainly on the brain cause the feeling of drowsiness and drunkenness, color vision defects, tiredness, and confusion. The cause of death in animals and humans is possibly asphyxia-oxygen deprivation. Aside from its effects on humans, the styrene gas also affects the life of birds, cattle, rats and dogs. ${ }^{7}$ Dermal contact may cause irritation, itching and erythematous popular dermatitis. As styrene is absorbed through the skin, systemic 
toxicity including Central Nervous System depression occurrence is possible. ${ }^{10}$

The limited evidence for cancer from styrene in humans is from occupational studies showing increased risks for lymphohematopoietic cancers, such as leukemia and lymphoma, and genetic damage in the white blood cells, or lymphocytes, of workers exposed to styrene. There is also some evidence for increased risk of cancer in the pancreas or esophagus among some styrene workers, but the evidence is weaker than that for lymphohematopoietic cancers.

Exactly how styrene causes cancer is not fully understood, but styrene is converted, in laboratory animals and humans, to styrene-7,8-oxide, which is listed in the Report on Carcinogens as reasonably anticipated to be a human carcinogen. Styrene-7,8-oxide causes genetic damage and has been found in the blood of workers exposed to styrene.

\section{Suggestions or policies implementation}

It is very highly reactive and it will polymerize rapidly with a violent explosive reaction. This demands transportation, proper handling and storage by adding polymerization inhibitors in sufficient quantities throughout these operations. Besides, an environmental information system needs to be adopted and regulate the protection rules of environment. Policies need to implement to minimize the risk factor. ${ }^{11,12}$

\section{Conclusion}

Chemical gas tragedy happened in Visakhapatnam and people in thousands were affected and 12 were died due to leakage of styrene gas into atmosphere. In general, styrene is a toxic gas as it is inhaled by humans and causes respiratory issues. Also, it may spread to nearby locations and pollute the environment predominantly air and water. Hence, the proper care should be taken to decrease or reduce the risk factor. The government should take precautionary measures to decrease the risk of these types of leakages and also to decrease the risk factor to humans

\section{Acknowledgments}

G Satya Sree says thanks to Andhra Pradesh Pollution Control Board (APPCB) for providing fellowship APPCB/RF/2018-19/07.

\section{Funding}

None.

\section{Conflicts of interest}

The authors declare there are no conflicts of interest.

\section{References}

1. Reddy MK, Rama Rao KG, Rao IR. Air quality status of Visakhapatnam (India)-indices basis. Environ Monit Assess. 2004;95:1-12.

2. Kumar DSS. Air pollution in Visakhapatnam - an overview. Int $J$ Civil Engg. 2013;2(4):11-14.

3. India today article.

4. Eckerman I. The Bhopal gas leak: Analyses of causes and consequences by three different models. Journal of Loss Prevention in the Process Industries. 2005;18:213-217.

5. The times of India article.

6. LG polymers.

7. Tanaka M, Yamamoto K. US patent 2723299. 1955.

8. Kerry Satterthwaite. Brydson's plastics materials. 8th edn. 2017.

9. Alexandre C Dimian, Anton A Kiss. Applications in design and simulation of sustainable chemical processes. 2019 .

10. PHE publications gateway number: 2014790 Compendium of chemical hazards: styrene.

11. Agency for toxic substances \& disease registry.

12. Pubchem-styrene. 